EPiC Series in Built Environment
Volume 1, 2020, Pages 36-44
Associated Schools of Construction Proceed-
ings of the 56th Annual International Conference

\title{
Design and Student Perceptions of a Graduate Course on Managing Risk in Construction
}

\author{
Clifton B. Farnsworth, Ph.D., P.E. \\ Brigham Young University \\ Provo, Utah
}

\begin{abstract}
Risk is an inherent part of the construction industry. As such, it is essential to prepare graduates of construction management programs to recognize and deal with uncertainty appropriately. One way to help meet this demand is by incorporating risk principles throughout the curriculum. Dedicating an entire course to teaching risk management is also highly valuable, especially within the graduate curriculum. As the tools, methods, and processes for managing construction risk continue to evolve within the industry, academic institutions will similarly need to adjust their teaching strategies to help meet the need for their graduates to deal with risk appropriately. The purpose of this paper is to provide a case study for the design and layout of a graduate level course on managing risk in construction, and briefly identifies the key content covered and the techniques used to teach these principles. This paper further provides student perceptions regarding their experience, and serves as a valuable example of a construction risk management course.
\end{abstract}

Key Words: Construction Risk, Risk Management, Construction Education, Graduate Curriculum

\section{Introduction}

The construction industry is fraught with uncertainty, or simply construction risk. For example, there is uncertainty in projects, processes, and business decisions, as well as in technology, materials, and people. In short, this inherent risk is a challenging aspect of construction. In recent years, there has been an increased emphasis placed on understanding this uncertainty (McGraw Hill 2014), and providing tools to deal with construction related risks (CII 2010). As the tools, methods, and processes for managing risk continue to evolve within the industry, academic institutions similarly need to adjust their teaching strategies to help meet the need for their graduates to deal with risk appropriately. One appropriate way to help meet this demand is by incorporating risk management principles within the curriculum, and even dedicating an entire course to teaching risk management. This type of course is especially appropriate at the graduate level. The purpose of this paper is to provide a case study of one such course. The Managing Risk in Construction course was incorporated into the graduate curriculum of the Master's program in Construction Management at Brigham Young University in 2014. This paper demonstrates the current design and layout of the course, and provides student perceptions of their learning experiences within the course. 


\section{Review of Literature}

For vibrant graduate construction education programs, periodic adjustments must be made to course offerings to meet the changing demands of the industry (Arditi and Polat, 2010). Pillicer et al. (2013) provided a comparison of the various subjects being taught within construction management graduate courses with needed topics. Of the 27 different subject areas being taught within 300 different graduate courses across the 21 leading international institutions analyzed, risk management ranked eighth. This equates to a risk management course being taught in only about half of the institutions. On the other hand, the research further identified risk management as one of the topics needing to be included more often within graduate curriculum. This literature validates the need for more risk management within construction management graduate curriculum.

During the development of the Managing Risk in Construction course at Brigham Young University, the literature was explored to also see what had been written about the topic in general, but even more specifically seeking examples for similar courses and potential materials to build the course upon. Two papers were identified that specifically discussed the creation of this type of course. First, Slattery and Bodapati (2001) described the type of content covered in their Risk Management of Construction course. The focus of the paper was to provide an overview of the risk management fundamentals and various sources of risk covered within the course. The paper also generally described the approach to student learning; however, the paper provided limited information regarding learning outcomes or source materials. The second paper focused more on the actual processes associated with risk management that were to be covered in the course (Sillars, 2005). Two additional papers discussing a similar graduate course have been published more recently. Panthi and Connell (2015) and Panthi and Diab (2017) detail the process of setting up a similar course for effective learning in an online environment. However, both of these papers focus more on the processes involved with developing a course and presenting material, including the significant learning approach and the just-in-time teaching technique, rather than what is being taught in the course. The purpose of this paper is to build upon this previous literature by providing a more complete example of content and materials, teaching strategies employed, and student feedback regarding this approach.

\section{Course Case Study}

The purpose of this section is twofold. First, the design and layout of the course is described. This is provided as an example of what the layout for a risk management course can look like. This template may be useful for other institutions that are looking to create a similar course, or for others simply looking for ideas of how to incorporate risk management content within their existing curriculum. Second, student perceptions regarding this course are provided. This information helps to emphasize those elements of the course that are effective, and illustrate the sections of the course that still need to be improved. The two elements contained within this section are mutually reinforcing and essential elements in demonstrating and validating the course, ultimately presenting the course case study for the Managing Risk in Construction course.

\section{Course Design}

The idea for a risk management course in the Construction Management graduate program at Brigham Young University was conceived in 2012, as part of the process for overhauling the graduate curriculum. Although elements of risk management were already being taught within the graduate curriculum, it was decided that it would be appropriate to dedicate an entire course to the topic. Thus, 
the new Managing Risk in Construction course was proposed and approved as part of the graduate curriculum. The first offering of the course took place in the Winter Semester of 2014, and has been taught every Winter Semester since (a total of six times). A single instructor (the author) has been involved in the development of the course and taught all six offerings. Although a number of modifications have been made to the course through the years, the number and magnitude of modifications has drastically decreased over time as the course curriculum has reached a stable point. This section of the paper represents a summary of the curriculum that is currently being utilized in the course. It is presented herein because of the unique nature of the course and the example it can provide for other institutions.

The biggest task initially faced was development of course content. There were three principal elements used for content development: searching for a textbook OR other appropriate supporting materials, visiting with industry professionals, and attending construction risk related workshops and conferences. A number of construction risk related books were located, but when it became apparent that an appropriate textbook was not going to be located, it was determined that the course would have to be developed from scratch. However, during this time, the instructor became aware of the Construction Industry Institute (CII) documents and tools related to managing construction risk. Although none of these materials would alone suit the purpose as a sole textbook for the full course, it was readily apparent that this material would greatly contribute to the course for two reasons: first, the material specifically addressed key elements of managing construction risk, and second, the materials are made available free of charge for students and faculty to use in academic institutions. Azhar et al. (2014) describe the benefits of using these of materials for teaching graduate courses, and these materials have served as the framework for the course content since its inception. However, regular student and industry feedback has driven the evolution of this course. The following summary of course content represents the most recent course offering. The material is presented herein, broken down by weekly topics and includes corresponding learning outcomes.

Week 1: Introduction to Project Risk and Risk Management: Learning outcomes: 1) explain risk and uncertainty, and 2) explain how risk management applies to life. Students begin the semester within a context they are familiar with - life related risk. The material is centered on the definition of risk (any uncertain outcome) and that risk can have either positive or negative outcomes.

Week 2: Key Construction Industry Risks: Learning outcome: 1) Identify and explain Schleifer construction business risks. Students read and present about key construction company risks (for example, "increasing project size" or "changing geographic location") from The Contractor's Guide to Success and Survival Strategies (Schleifer et al. 2014). The material focuses on risks that commonly lead to economic problems for construction companies.

Week 3: Identifying Risk: Learning outcomes: 1) Explain categories of risk in construction, 2) identify potential construction risk, and 3 ) create a risk register. The students begin their first semester project, a large high risk heavy civil construction project. The students are given the construction documents (plan set and specifications). Students become familiar with lists of common potential risk (Loosemore et al. 2006) and specifically begin to identify risk on the case study project.

Week 4: Assessing Risk: Learning outcomes: 1) explain processes for risk management in construction, 2) explain company risk maturity, 3) explain deterministic methods of assessing risk, 4) determine time and cost variables for project risk, and 5) perform a deterministic risk assessment. Students begin utilizing the CII risk management documents and risk prioritization tools (CII 2010, CII 2012). Students also perform a deterministic analysis of their identified project risks. 
Week 5: Prioritizing Risk: Learning outcomes: 1) explain probabilistic methods of assessing risk, 2) determine ranges of time and cost variables for project risk and appropriate distribution functions, and 3) perform a probabilistic analysis. Students perform a Monte Carlo probabilistic simulation and compare different prioritization methods. Rather than having students focus on using commercially available Monte Carlo software, students develop a Monte Carlo spreadsheet so that they can demonstrate the internal workings of the probabilistic simulation.

Week 6: Case Study on Risk in Project Management: Learning outcome: 1) explain risk strategies on an actual construction project. In this module students experience a virtual field trip of their first semester project. Students also read several documents related to the actual risk encountered on the case study project (Farnsworth 2016, Farnsworth et al. 2007). This gives the students a relative comparison of their determined risks compared to those actually encountered on the project.

Week 7: Equitable Risk Allocation: Learning outcomes: 1) explain equitable risk allocation, 2) explain 14 hot button risks, and 3) perform equitable risk allocation. In this module students are introduced to the idea of risk allocation and distributing and sharing risk appropriately (CII 2006). Students also use the CII equitable risk allocation tools to determine appropriate risk designation.

Week 8: Hot Button Risks: This week is used as a workweek, to take the first midterm and research and prepare presentations on the 14 "hot button" risks (CII 2006) (for example, "no damages for delay" or "ambiguous acceptance criteria"). Emphasis is given on understanding contract language that favors either the buyer, seller, or a compromise.

Week 9: Contract Risk Assessment: Learning outcomes: 1) analyze a contract for hot button risks and determine whom the language favors, and 2) rewrite contract language for equitable allocation. Students present their "hot button" risk research, and perform a risk assessment comparing and contrasting two different contracts.

Week 10: Professional and General Liability Insurance Risk: Learning outcomes: 1) explain key liability risks, and 2) assess a project for potential key liability risks. Emphasis is placed on different types of insurances and bonds used within the construction industry. This is a great topic to bring in an industry expert as a guest instructor.

Week 11: Group Project-Large Commercial Building: This week is used as a workweek for the students to begin the second semester project - essentially applying everything learned to this point in the semester on a large commercial construction project. Students are given the construction documents (plan set and specifications), and incorporate all tools developed throughout the semester.

Week 12: Managing Uncertainty and Expectations: Learning outcomes: 1) explain ten key findings regarding project uncertainty, and 2) explain how to incorporate these findings on a project. In this module emphasis is placed on current management related risks found in the construction industry (McGraw Hill 2014, Hoover et al. 2016). Another focus is on construction claims prevention.

Week 13: Management Risks - Trust: Learning outcomes: explain how contract language can establish higher ground, and 2) explain key management risks and how they apply to construction. The focus of this module is people and relationship risk (Connors et al. 2010). This module also has more of a "leadership" tone to it, with regard to managing risk. As part of this module students read The Speed of Trust (Covey 2006) and write a personal reflection paper on what they learned. 
Week 14: Resiliency: Learning outcomes: 1) explain the black swan event, and 2) explain how to effectively minimize the effects of black swan events. This module emphasizes resiliency in the face of risk occurrences, especially for a "black swan" event (Taleb 2010).

Week 15: Project Presentations: In addition to a final exam, students also present their final risk analysis on the large commercial building project, and demonstrate how they incorporated all elements learned during the semester.

\section{Student Perceptions}

At the end of each semester that the Managing Risk in Construction course has been taught, a survey was provided to the students in the class to get feedback about their experiences in the course. This survey supplemented the standard university student ratings survey, by seeking to understand student perceptions regarding specific aspects the course not readily obtained through the university student ratings. This included gathering detailed feedback about the content covered, materials used, and the assignments given, specifically seeking to obtain both positive and negative perceptions from each student. For example, students were asked to identify the three things they liked most about the course, as well as the three things that they disliked most about the course. The principal purpose behind these surveys was to better understand the student experience, to be able to make informed decisions regarding effective modifications to the course and continually strengthen it. This feedback has been valuable for replicating things that are going well and making changes with those parts of the course that aren't as meaningful to the students. The feedback summarized here is based on the responses of 28 of the 32 students taking the course over the past six years. This section represents some of the feedback regarding the course that was obtained during this process.

\section{Reading Material}

Students generally had positive feedback regarding the CII managing construction risk resources used. They indicated that the reading felt practical, was up to date and clearly from reliable sources, and very informational. The materials were also clear and gave specific examples. One student comment seems to represent the general sentiment well; "I like that it came from industry experts. I really felt like we were dealing with best practices and modern tools to manage risk." Although the general sentiment regarding CII reading material has been positive, initially there were several negative comments. Some of the reports were a little on the lengthy side and at times a little more theoretical than what students preferred. The instructor did find that keeping reading assignments to no more than around 50 pages a week (especially for the more theoretical material) and targeting specific sections of the material, worked better than simply asking the students to "read the report." Additionally, it was more effective to give the students an overview of the purpose behind the reading and what they were expected to get out of it. This approach of intentional reading has been demonstrated to be an effective form of active learning (Svinicki and McKeachie, 2014). The negative feedback regarding the CII reports has essentially been eliminated since incorporating the intentional reading approach.

The Speed of Trust book (Covey 2006) was added to the course within the most recent two course offerings. Much of the literature used in the class refers back to communication related issues as a principal contributor to the occurrence of risk events on construction projects; therefore, the instructor was looking for a resource that could really help students find specific ways to begin to bridge this issue. The Speed of Trust ended up being the perfect addition to the course. After discussing communication challenges throughout the early parts of the semester, the book really offers the students a number of high level practical ideas for more effectively interacting with others within the industry. The construction industry is often touted as a "people industry," and this book provides the 
students with an overview of effective leadership principles and processes for overcoming the challenges associated with dealing with people. Students have responded favorably to this assignment and indicate that it has become one of their favorite learning experiences in the course.

\section{Risk Analysis Projects}

Another key element of this course has been the group risk analysis projects. Both group-based and problem-based learning have also been shown to be effective forms of helping students learn effectively (Svinicki and McKeachie, 2014). Performing a risk assessment and developing a risk management plan for multiple projects during the semester follows the effective pedagogy strategies of spaced practice (Brown et al. 2014). In essence this means that students are given multiple chances to practice applying the principles spread across the semester, a technique proven to effectively increase retention. Students have specifically noted that they like that there are two projects given in the class, and that the first project is used in a "step-by-step" manner to help the students understand what the whole process looks like as the early course material is being taught. They further appreciate that the projects are dissimilar, one being a heavy-civil project and the other a commercial project. Students have indicated that this forces them to continue to stretch themselves on the second project and not simply replicate what they did the first time through. This is known as "varied practice." Applying principles in different scenarios has also been shown to help students more effectively learn the material (Brown et al., 2014). Finally, students indicate that using actual projects is a practical way to explore project and process risk, analyze cost and mitigation strategies, and an effective way to learn how to use and apply risk tools. Surprisingly, one of the elements most liked in the course was performing a Monte Carlo simulation on an actual project. Students indicate that it was especially useful to perform it "from scratch" using a spreadsheet, as opposed to simply learning how to use a commercial software platform. Students specifically noted that this helps them better visualize and understand what is actually happening with the data during the Monte Carlo process.

One of the key challenges regarding the projects regularly expressed by students is the inability to know what type of numbers are reasonable for different types of risk. One student summed it up well when indicating that they felt like the "were just playing make-believe" with the numbers.

Unfortunately, determining realistic estimates for both the dollar and time values associated with specific risks requires a great deal of experience, something that students typically do not have. The course itself focuses more on the processes associated with identifying and analyzing risk, than the actual magnitude of the cost and schedule contingency outputs, and students are graded correspondingly. It should further be noted, that the estimates students provide are typically in the right ballpark, ensuring that the experience students are having is realistic. On a positive note, at least the students are recognizing the necessity of providing confident practical estimates, thus leading to realistic results. However, because this continues to surface as a concern, the instructor also continues to look for more effective ways to help students gain more confidence in their risk response estimates.

\section{Insurance and Contracts}

The importance of understanding insurance and contracts with regard to managing construction risk cannot be overstated. However, this continues to be one of the more challenging aspects of the course. The most meaningful learning experiences seem to have come from guest speakers (at least in terms of positive student feedback). One semester, a guest speaker from a large national level construction insurance company was invited to come (traveling all the way from New York City at their own expense), and made a fascinating presentation regarding the industry drivers of insurance claims for their company. The data from this presentation was made available to the instructor and continues to be shared each semester. However, it was far more impactful when being presented by the actual data 
owners, rather than simply being shared by the instructor. Multiple other guest speakers have come to present about insurance and contracts over the various semesters that this course has been taught. However, finding the right guest speakers to complement course content is key. The instructor has had both positive and negative experiences with this. However, students almost inevitably are appreciative of a good guest speaker and count it as one of the better learning experiences of the semester. This approach is especially useful if the instructor has limited experience with insurance and contracts. Another effective method that has been used is to send the students to meet with industry representatives outside of class time and visit with them about their insurance and contracting methods. This approach also seems to be well received by students.

Despite the positive feedback that has come from industry interaction, students continue to seek additional help regarding interpreting confusing contract language. One of the biggest difficulties encountered is finding consistency in industry input regarding contract language. However, the addition of the CII "hot button" risk language and associated documents has had a positive effect on the contract language module of the course. The CII document provides a research based consistent approach to analyzing contracts, and greatly helps students better understand and identify language that favors the buyer, seller, or a shared approach. This has further enhanced the students' ability to analyze a contract and given them specific elements to look for when doing so. Unfortunately, the instructor anticipates that this will continue to be an element that gets negative feedback from the students. Perhaps the best way to help the students strengthen their understanding of contract language is to give them more practice with contracts. However, despite acknowledging that this is a part of the course that should improve, most of the students don't seem to want to spend any more time with it. Learning about contracts and insurance language continues to be commonly acknowledged as one of the most disliked elements of the course. Perhaps it is simply the nature of the topic; either way, this is one of area of the course that the instructor continues to work on making more effective.

\section{Course Value}

As part of the end of semester survey, students were asked to identify those topics from the course that they anticipate will be of most value to them during their career. There are five elements that tend to be most commonly identified, including the following: 1) thinking about risk in terms of being both positive and negative (risk encompasses both threats and opportunities), 2) the ability to recognize risks and prioritize them effectively using appropriate methods, 3) equitable risk allocation principles are essential for getting the risk to the most effective party, and are most effectively practiced through partnering and other collaborative techniques, 4) recognizing that different, yet equally important, perspectives exist between owners, contractors, and engineers, and 5) construction risk extends beyond project risk and includes relationships, communication, and business level decision making.

The first three elements that students identify with as providing value are straight from the course material from the first half of the semester, and represent the heart of the applied content performed in the course projects. The fourth element seems to be an interesting anomaly that occurs primarily because the course tends to be made up of a mix of construction management and civil engineering students. One engineering student indicated that they "felt like the contractor's point of view was a paradigm shift" and that gaining this perspective would help them "better understand and work with them in the field." Similar comments were made by construction management students regarding working with engineering students. Working in mixed groups allowed students to "bring ideas and different points of view together" and "see issues from different angles." Opening up the door for this mutual respect and understanding has been one of the most significant indirect outcomes of this course. It is the opinion of the instructor that one of the biggest strengths in this course is the interaction that develops between civil engineering and construction management students as they 
work to identify and analyze risk together. It is, therefore, fitting that the students also acknowledge this as a value experience in the course. Finally, this course has helped students capture a greater vision of managing risk on a business level. Students seem to have captured a greater vision of the importance of risk management as a business strategy and culture. One student indicated that there will come a point in their career that they are "no longer a number cruncher," and it is important to understand the different types of risks that come from "being in charge of business aspects as well." Capturing this vision is an essential outcome of having this course taught at the graduate level.

\section{Conclusions}

Risk is an inherently challenging aspect of the construction industry. In the recent past, there has been more emphasis placed on providing ways to deal with construction related risks. As the tools, methods, and processes for managing risk continue to evolve within the industry, academic institutions similarly need to adjust their teaching strategies to help meet the need for their graduates to deal with risk appropriately. One appropriate way to do this is by dedicating an entire graduate level course to teaching risk management principles. This paper provides an example of such a course, and includes the design and layout of the Managing Risk in Construction course and a summary of the student perceptions regarding their learning experience. This paper specifically adds to the body of knowledge by providing a case history for this type of graduate curriculum. One key lesson includes teaching the course through a project based approach, using multiple (and very different) construction projects. Construction risk management resources made available by the Construction Industry Institute (CII) serve as exceptional teaching materials and tools. Insurance and contracts tend to be the most difficult topics to teach, but can be greatly enhanced through industry involvement. Interaction between civil engineering and construction management students in the course has also greatly enhanced the learning environment. Ultimately, students provide favorable feedback regarding their experience, and overwhelmingly find value in this course.

\section{References}

Arditi, D. and Polat, G. (2010). "Graduate Education in Construction Management." Journal of Professional Issues in Engineering Education and Practice, 136(3): 175-179.

Azhar, S. Grau, D., Burt, R., and Gibson, G.E. (2014). "State-of-the-Art Best Construction Practices Integration into Higher Education Curricula." Journal of Professional Issues in Engineering Education and Practice, 140(1): 04013005.

Brown, P.C., Roediger III, H.L., and McDaniel, M.A. (2014). Make it Stick. Cambridge, MA: Harvard Academic Press.

CII (2006). Equitable Risk Allocation. Construction Industry Institute, Research Summary 210-1.

CII (2010). Management of Project Risks and Uncertainties. Construction Industry Institute, Research Summary 6-8 (v. 1.1).

CII (2012). Probabilistic Risk Management in Design and Construction Projects. Construction Industry Institute, Research Summary 280-1 (v. 1.1). 
Connors, R., Smith, T., Hickman, C. (2010). The Oz Principle: Getting Results through Individual and Organizational Accountability. London, Portfolio.

Covey, S.M.R. (2006). The Speed of Trust: The One Thing That Changes Everything. New York, Free Press.

Farnsworth, C.B. (2016). "Challenges with Managing Risk when Using the Observational Method of Construction with Design-Bid-Build Delivery." ASCE Construction Research Congress, San Juan, Puerto Rico.

Farnsworth, C.B., Lee, T.S., Cline, M., and Golden, J.W. (2007). "Construction Challenges Associated with the Provo Canyon, Utah Widening Project." $1^{\text {st }}$ North American Landslide Conference, Vail, Colorado.

Hoover, S., Howsam, R., Trombitas, P., and Kennedy, M. (2016). "Managing and Mitigating Risk in Today's Construction Environment." AGC/FMI Industry Survey, Associated General Contractors of America and Fails Management Institute.

Loosemore, M., Raftery, J., Reilly, C., and Higgon, D. (2006). Risk Management in Projects ( $2^{\text {nd }}$ ed.). New York: Taylor and Francis.

McGraw Hill (2014). "Managing Uncertainty and Expectations in Building Design and Construction." McGraw Hill Construction, SmartMarket Report.

Panthi, K. and Connell, E. (2015). "Designing an Online Graduate Level Course in Construction Risk Management using the Significant Learning Approach.” ASC Annual Conference Proceedings.

Panthi, K. and Diab, M.F. (2017). "Design and Delivery of an Online Graduate Course in Risk Management Using Significant Learning and Just-in-Time Teaching Approach.” ASC Annual Conference Proceedings.

Pelllicer, E., Yepes, V., and Ortega, A.J. (2013). "Method for Planning Graduate Programs in Construction Management." Journal of Professional Issues in Engineering Education and Practice, 139(1): 33-41.

Schleifer, T.C., Sullivan, K.T., and Murdough, J.M. (2014). Managing the Profitable Construction Business: The Contractor's Guide to Success and Survival Strategies ( $2^{\text {nd }}$ ed.). Hoboken, New Jersey: Wiley.

Sillars, D.N. (2005). "Developing a Graduate-Level Course in Construction Risk." ASC Annual Conference Proceedings.

Slattery, K. and Bodapati, N. (2001). "Risk Management of Construction - A Graduate Course.” ASC Annual Conference Proceedings.

Svinicki, M.D. and McKeachie, W.J. (2014). Teaching Tips (4 ${ }^{\text {th }}$ ed.). Belmont, California: Wadsworth, Cengage Learning.

Taleb, N.N. (2010). The Black Swan: The Impact of the Highly Improbable. New York, Random House. 